\title{
Comparison of sleep in osteoarthritic patients and age and sex matched healthy controls
}

\author{
T J LEIGH, ${ }^{12}$ I HINDMARCH, ${ }^{2}$ H A BIRD,${ }^{1}$ AND V WRIGHT ${ }^{1}$
}

From the ${ }^{1}$ Clinical Pharmacology Unit, Regional Rheumatology Centre, Royal Bath Hospital, Harrogate and Rheumatism Research Unit, University of Leeds; and the ${ }^{2}$ Human Psychopharmacology Research Unit, University of Leeds

SUMmaRY A sleep laboratory comparison of the sleep of 14 osteoarthritic patients with that 16 age and sex matched healthy controls was undertaken. After three nights of adaptation continuous recordings of electroencephalographic (EEG), electro-oculographic (EOG), and electromyographic (EMG) activity were obtained for the next two nights. A comparison of EEG sleep variables during this baseline period showed that osteoarthritic patients had a significantly greater percentage of stage 1 and significantly smaller percentage of stage 2 sleep than controf subjects. These findings indicate sleep disturbance in osteoarthritic patients. The limited degree of disturbance observed in these patients may be due to the fact that they were allowed to continue wit their normal anti-inflammatory and analgesic medication for the course of the study.

Key words: EEG, sleep disturbance, pain.

Many patients with rheumatic diseases complain of insomnia. Its management has been the subject of earlier studies. ${ }^{1-3}$ Pain, ${ }^{13}$ stiffness, ${ }^{2}$ and muscular discomfort ${ }^{4}$ have been cited as possible causes of the insomnia. Much of the work on sleep in rheumatic diseases has been based on the patients' subjective impressions. A number of studies have evaluated objective EEG sleep variables in non-rheumatic patient groups and made useful comparisons with age matched normal subjects. ${ }^{5-8}$ There have only been a few such studies with rheumatic patients. Moldofsky et al obtained all-night EEG recordings from a group of fibrositic patients. ${ }^{9}$ Part of this study involved a comparison of EEG sleep variables in fibrositic patients with those in normals, though the control results were recorded by another laboratory. ${ }^{10}$ As part of a larger study, in which we hope to investigate the cause and possible treatment of sleep disturbance in different rheumatic conditions, we have constructed a sleep laboratory in a hospital for rheumatic diseases and used this to compare the sleep of 14 osteoarthritic patients with that of 16 age and sex matched healthy controls.

\section{Patients and methods}

S U B J E C T S

Sixteen male osteoarthritic patients entered the

Accepted for publication 3 June 1987.

Correspondence to Dr T J Leigh, Clinical Pharmacology Unit, Royal Bath Hospital, Cornwall Road, Harrogate, North Yorkshire HG1 2PS. study, but two withdrew for personal reasons. A had radiological evidence of osteoarthritis of the hio or knee, or both, and all had symptoms sufficient merit admission to a hospital for rheumatic diseases for intensive physiotherapy and consideration replacement joint surgery. The 14 patients who completed the study were aged 52-70 (mean 6 years, had no history of psychiatric or severie physical (hepatic, renal, or cardiac) disease, and were able to follow simple instructions. With the exception of psychotropic drugs, which were forbid den for six weeks before and during the studß, patients continued with their usual medication. Sixteen healthy male controls aged 52-70 (mean 62) years were studied. They had no history of sleep disorders and were able to follow simple instrue. tions. The controls were not prescribed any drugs for six weeks before and during the study. For the duration of the study all subjects were required no to take daytime naps, unusual violent exercise alcohol, or caffeinated beverages after lunchtime्,

\section{PROCEDURE}

Subjects slept in a sleep laboratory for five nights They were given a placebo elixir each night. The first three nights were for adaptation. ${ }^{n}$ Thref adaptation nights were used instead of the custorf ary one because it has been suggested that older subjects may need a longer adaptation period Nights 4 and 5 served as a baseline, which was used 
Table 1 Mean baseline and (standard deviation) for EEG sleep variables in osteoarthritic patients and controls

\begin{tabular}{|c|c|c|c|}
\hline Variable & $\begin{array}{l}\text { Osteoarthritic } \\
\text { patients }\end{array}$ & Controls & $\begin{array}{l}\text { Significance of group } \\
\text { difference }\end{array}$ \\
\hline Sleep latency $(\mathrm{min})$ & $16 \cdot 2(6 \cdot 0)$ & $18.7(10.7)$ & NS \\
\hline Sleep efficiency (\%) & $81.5(7.9)$ & $80 \cdot 4(7 \cdot 7)$ & NS \\
\hline Number of awakenings & $18.3(7.7)$ & $19.7(5.8)$ & NS \\
\hline Duration of awakenings (min) & $102 \cdot 8(38 \cdot 2)$ & $85.3(37.0)$ & NS \\
\hline Number of shifts to stages $(0+1)$ & $37.0(13.5)$ & $36.5(8.7)$ & NS \\
\hline Stage $0(\%)$ & $9.2(4.9)$ & $10.9(7.0)$ & NS \\
\hline Stage $1(\%)$ & $23.6(6.9)$ & $15 \cdot 2(3.9)$ & $p<0.001$ \\
\hline Stage $2(\%)$ & $47 \cdot 7(8 \cdot 2)$ & $54.4(7.8)$ & $p<0.05$ \\
\hline Stages $(3+4)(\%)$ & $0.3(0.3)$ & $1.1(1.5)$ & NS \\
\hline Stages $(0+1)(\%)$ & $32.7(9.8)$ & $26.0(8 \cdot 3)$ & NS \\
\hline Stage REM $(\%)$ & $19.3(4.5)$ & $18.5(4.4)$ & NS \\
\hline REM latency (min) & $62.4(24.8)$ & $68 \cdot 8(22 \cdot 6)$ & NS \\
\hline
\end{tabular}

to compare sleep in osteoarthritic patients and controls. On these nights the EEG, EOG, and EMG were recorded with a Disa (model 26A10) polygraph, using standard electrode placements for all night polysomnography. ${ }^{13}$ During the adaptation period electrodes were attached, but no recordings were taken. Throughout the study subjects retired at 22.30 hours and were woken at 06.00 hours each day. Subjects slept in comfortable, light proofed, sound attenuated bedrooms. All EEG records were scored in 30 second epochs according to the criteria of Rechtschaffen and Kales. ${ }^{13}$ From the scored records 12 EEG sleep variables were derived (see Table 1).

\section{STATISTICAL ANALYSIS}

Two planned comparisons were carried out on each of the 12 EEG sleep variables using one way analysis of variance. The first compared baseline night averages of the osteoarthritic patient group with those of the control group and the second involved a baseline night 1 versus baseline night 2 comparison within each of the two groups. The significance level for differences between means was $\mathrm{p}<0.05$.

\section{Results}

Table 1 gives the results of the baseline night average comparison of osteoarthritic patients and controls. This comparison showed that the patients had a greater percentage of stage 1 sleep $(p<0.001)$ and a smaller percentage of stage 2 sleep $(p<0.05)$ than the controls. The only significant difference in the sleep of controls on the first and second baseline nights was an increased number of awakenings on the second baseline night $(p<0 \cdot 05)$. In the osteoarthritic patients there were no significant differences between the two baseline nights.

\section{Discussion}

With the exception of psychotropic drugs, which were discontinued, osteoarthritic patients continued with their usual drug regimen throughout the course of the study. Such medication was needed on ethical grounds as most of these patients had severe pain and discomfort. It also enabled a realistic evaluation of sleep in osteoarthritic patients, most of whom would normally be receiving anti-inflammatory or analgesic medication, or both.

The purpose of the baseline night 1 versus baseline night 2 comparison within each of the two groups was to check that sleep was similar on both baseline nights. Differences between baseline nights could be due to an incomplete adaptation to the sleep laboratory or marked night to night variation in either group. The only significant difference observed was with the controls, who had an increased number of awakenings on the second baseline night. This finding is the opposite of that which might be expected if the controls were incompletely adapted to the sleep laboratory, because adaptation and therefore sleep would improve with successive nights.

The average of the baseline nights was considered the most representative of normal sleep and was used in the comparison of sleep in osteoarthritic patients and controls. The increased percentage stage 1 sleep and reduced percentage stage 2 sleep observed in the osteoarthritic patients is indicative of sleep disturbance. Stage 1 sleep, or drowsiness, is considered so close to wakefulness that many researchers (including the authors) use stage 2 rather than stage 1 as an indication of sleep onset. ${ }^{14}$ Although the patients continued with their routine medication, significant differences were observed between the two groups. If the osteoarthritic patients had been deprived of their analgesics and anti-inflammatory medication it is possible that the degree of sleep disturbance would have been much worse. The previous comparison by Moldofsky et al 
of EEG sleep variables in fibrositic patients and normals also showed a difference in stage 1 sleep, the fibrositic group spending about twice as long in this stage. ${ }^{9}$

Differences in EEG sleep variables have been reported in a number of chronic diseases. Patients with angina showed significantly longer sleep latencies, reduced stages 3 and 4 , and less efficient sleep than healthy controls. ${ }^{6}$ Asthmatic patients also showed differences, including significantly less total sleep time and stage 4 sleep than normal controls. ${ }^{5}$ These findings suggest that sleep disturbance represents a non-specific change resulting from many predisposing factors. In osteoarthritis the stimulus for its occurrence might arise from the joints or muscles.

This demonstration of an objective difference in the sleep of osteoarthritic patients lends weight to the consideration of sleep disturbance as an indication for arthroplasty or other surgical intervention. Studies are in progress to determine whether surgery improves sleep in osteoarthritis and whether it is the use of analgesics, anti-inflammatory agents, hypnotic drugs, or combinations of these that best improve sleep.

The authors are grateful to Patrick Constable for statistical advice and Brian Hickey for help with the data analysis. The study was supported in part by a research grant from Farmitalia Carlo Erba Ltd. We are grateful for financial help from the locally organised clinical research funds.

\section{References}

1 Bayley T R L, Haslock I. Night medication in rheumato arthritis. J R Coll Gen Pract 1976; 26: 591-4.

2 Condie R. Chlormezanone in the treatment of insomnia due rheumatic stiffness. Curr Med Res Opin 1979; 6: 217-20. 음

3 Wojtulewski J A, Walter J. Treatment of sleep disturbance arthritis with chlormezanone. Curr Med Res Opin 1983; 456-60.

4 Cohen L. A controlled study of Trancopal in sleep disturbance्s due to rheumatic disease. J Int Med Res 1978; 6: 111-4. $\vec{P}$

5 Kales A, Beall G N, Bajor G F, Jacobson A, Kales J D. Sleep studies in asthmatic adults: relationship of attacks to sleep stage and time of night. Journal of Allergy 1968; 41: 164-73.

6 Karacan I, Williams R L, Taylor W J. Sleep characteristics patients with angina pectoris. Psychosomatics 1969; 10: 280-5

7 Frankel B L, Coursey R D, Buchbinder R, Snyder F. Recordêd and reported sleep in chronic primary insomnia. Arch Gẹt Psychiatry 1976; 33: 615-23.

8 Brezinova V, Catterall J R, Douglas N J, Calverley P M is Flenley D C. Night sleep of patients with chronic ventilatogy failure and age matched controls: number and duration of the EEG episodes of intervening wakefulness and drowsiness. Sleepp 1982; 5: $123-30$.

9 Moldofsky H, Scarisbrick P, England R, Smythe H. Muscule skeletal symptoms and non-REM sleep disturbance in patierws with 'fibrositis syndrome' and healthy subjects. Psychosom Med 1975; 37: 341-51.

10 Williams R L, Karacan I, Thornby J I, Salis P J. Th electroencephalogram sleep patterns of middle-aged males? J Nerv Ment Dis 1972; 154: 22-30.

11 Agnew Jr H W, Webb W B, Williams R L. The first nige effect: an EEG study of sleep. Psychophysiology 1966; 2: 263-

12 Herbert. In a discussion following a paper by Gerard P, Colli K J, Dove C, Exton-Smith A N. Subjective characteristics sleep in the elderly. Age Ageing 1978; 7: 55-63.

13 Rechtschaffen A, Kales A. A manual of standardized terminof ogy, techniques and scoring system for sleep stages of hum subjects. NIH Publication. Washington DC: US Governme Printing Office, 1968: No 204.

14 Oswald I. Sleep studies in clinical pharmacology. Br J C Pharmacol 1980; 10: 317-26. 